\title{
Clinical implications of pulmonary rehabilitation
}

\author{
Roger Goldstein MB ChB FRCPC FRCP(UK)
}

T he burden of chronic obstructive pulmonary disease (COPD)

has grown in recent years, making it the fourth most important cause of morbidity and mortality in Canada. The dramatic rise in COPD prevalence among women reflects increased smoking rates for women over the past 20 years. Many professional societies recommend rehabilitation, as part of COPD management, to increase health-related quality of life and improve functional exercise capacity. Rehabilitation is associated with a reduction in health resource utilization. Unfortunately, its benefits diminish with time. Current challenges include identifying the most effective approaches to rehabilitation in terms of location, essential components and ways to maintain the initial program benefits.

\section{COPD - A MAJOR PROBLEM}

COPD is a global health care challenge (1), predicted to move from the 12 th to the fifth most important cause of mortality by 2020 (Figure 1). Data from the United States (1965 to 1998) reflect the increase in COPD concomitant with the gradual reduction in coronary artery disease, stroke and other cardiovascular conditions (Figure 2) (2). In Canada, data concerning physician-diagnosed COPD from 1998 to 1999 showed that in the age group from 55 to 74 years, more women than men were diagnosed with COPD (Figure 3). Post-2002, the number of women dying from COPD is predicted to greatly exceed the number of men (Figure 4) (3).

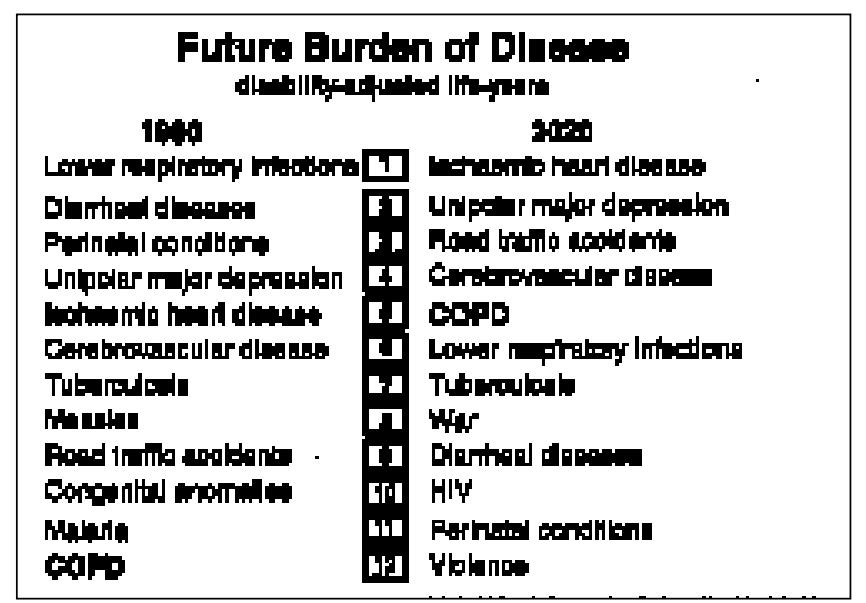

Figure 1) Future burden of disease (disability-adjusted life-years) predicting that COPD will move from the 12th cause to the fifth cause globally by 2020. COPD Chronic obstructive pulmonary disease; HIV Human immunodeficiency virus. Data taken from reference 1

\section{MANAGEMENT OF COPD}

The clinical goals of COPD management include preventing further reduction in airflow, improving dyspnea and functional exercise capacity, and minimizing the impact of exacerbations. Clinically, this means secondary prevention (cessation

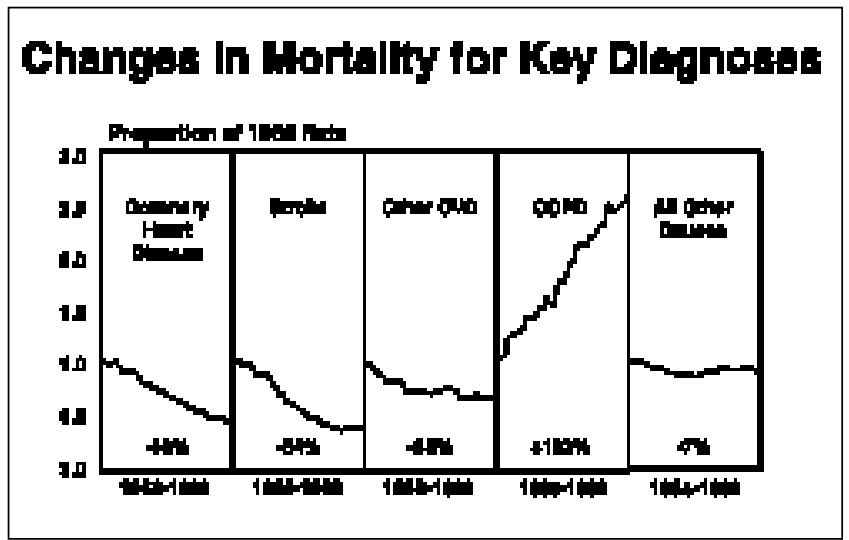

Figure 2) National Heart, Lung, and Blood Institute Chartbook on Cardiovascular and Pulmonary Disease - changes in mortality (United States) for key diagnostic categories showing the increase in chronic obstructive pulmonary disease (COPD) relative to the decrease in other causes. CVD Cardiovascular disease. Data taken from reference 2

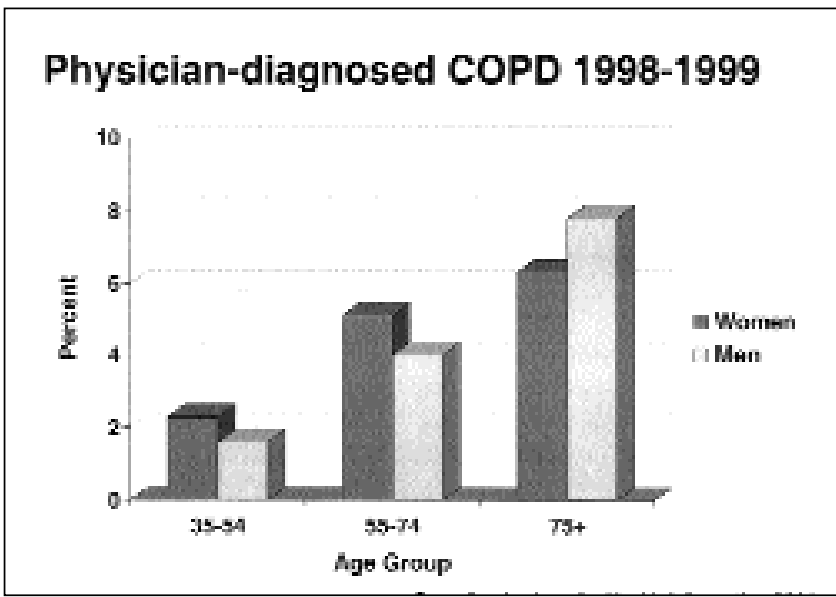

Figure 3) Canadian Institute for Health Information 2001 - histogram of physician-diagnosed chronic obstructive pulmonary disease (COPD) showing that in the age group of 55 to 74 years, women exceeded men in diagnoses in the time period from 1998 to 1999. Data taken from reference 3

Professor of Medicine and Physical Therapy, University of Toronto, Toronto, Ontario; National Sanitarium Chair in Respiratory Rehabilitation Research Correspondence: Dr Roger Goldstein, WestPark Healthcare Centre, 82 Buttonwood Avenue, Toronto, Ontario M6M 2J5. Telephone 416-243-3631, fax 416-243-8947, e-mail rgoldstein@westpark.org 


\section{COPD Degtha 1987-2016}

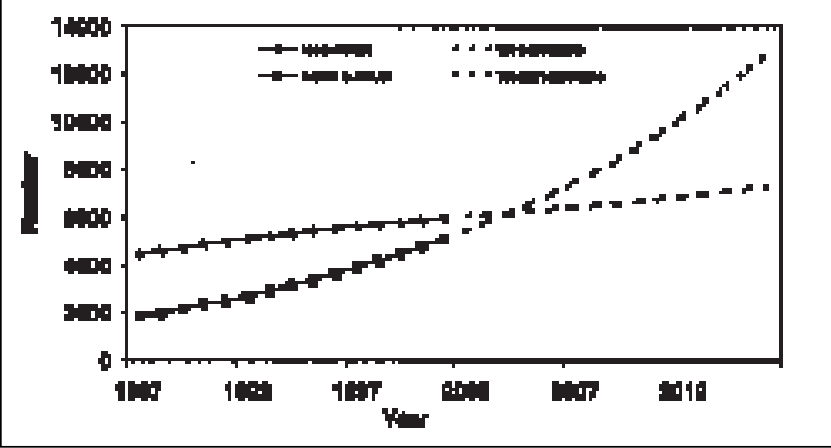

Figure 4) Canadian Institute for Health Information 2001 - Predicted deaths from chronic obstructive pulmonary disease (COPD) from 1987 to 2016. This figure shows the marked increase in mortality among women. Data taken from reference 3

\section{$\mathrm{RCT}$ of 6 week in-patient rehabilitation}

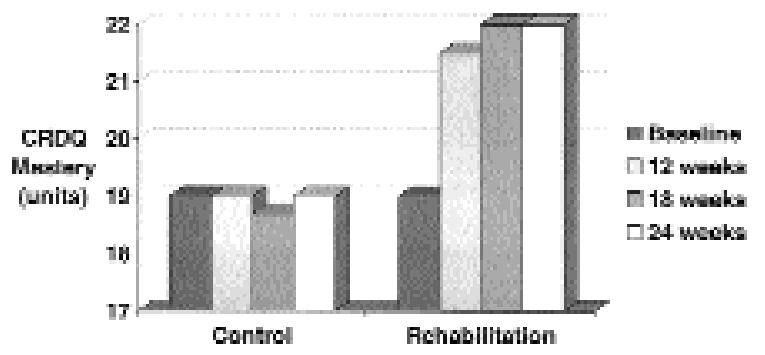

Figure 5) Results of a randomized, controlled trial (RCT) of six-week inpatient rehabilitation; figure shows the improvement in chronic respiratory disease questionnaire $(\mathrm{CRDQ})$ mastery following rehabilitation sustained at 24 weeks. Data taken from reference 4

of smoking, appropriate immunization), optimization of lung function (bronchodilators) and minimization of sequelae (oxygen, nutrition, rehabilitation and surgery). The primary respiratory impairment results in dyspnea from moderate exertion, abstention from exercise, deconditioning and, therefore, dyspnea during mild exertion. With further deconditioning and a sedentary lifestyle, activities of daily living may be markedly compromised.

\section{THE ROLE OF REHABILITATION}

Although primary lung impairments associated with chronic respiratory conditions are unlikely to change with rehabilitation, improvements in secondary impairments (respiratory muscle, peripheral muscle, cardiac, nutritional and psychosocial) have an important influence on the way that patients function.

The following points have emerged:

- Respiratory rehabilitation improves healthrelated quality of life and functional exercise capacity.
TABLE 1

Pulmonary rehabilitation for chronic obstructive pulmonary disease

\begin{tabular}{|c|c|c|c|c|}
\hline $\begin{array}{l}\text { Outcome } \\
\text { measures }\end{array}$ & Trials & $\begin{array}{l}\text { Patients } \\
\text { treated/ } \\
\text { controls }\end{array}$ & $\begin{array}{l}\text { Weighted } \\
\text { mean } \\
\text { differences }\end{array}$ & $95 \%$ Cls \\
\hline Dyspnea & 9 & $277 / 242$ & 1.0 CRQ units & $0.8-1.2 \mathrm{CRQ}$ units \\
\hline Fatigue & 8 & $273 / 240$ & $0.9 \mathrm{CRQ}$ units & $0.7-1.1 \mathrm{CRQ}$ units \\
\hline Emotional function & 8 & $273 / 240$ & $0.7 \mathrm{CRQ}$ units & 0.4-1.0 CRQ units \\
\hline Mastery & 8 & $273 / 240$ & $0.9 \mathrm{CRQ}$ units & $0.7-1.2 \mathrm{CRQ}$ units \\
\hline $\begin{array}{l}\text { Functional exercise } \\
\text { capacity }\end{array}$ & 10 & $238 / 219$ & $49 \mathrm{~m}$ & $26-72 \mathrm{~m}$ \\
\hline $\begin{array}{l}\text { Maximum exercise } \\
\text { capacity }\end{array}$ & 14 & $255 / 233$ & 5.4 Watts & $0.5-10.2$ Watts \\
\hline
\end{tabular}

This meta-analysis shows significant and clinically important improvements, especially in the domains of dyspnea, fatigue, emotional function and mastery. CRQ Chronic respiratory questionnaire. Data taken from reference 8

TABLE 2

Joint American College of Chest Physicians/American

Association of Cardiovascular and Pulmonary

Rehabilitation Guidelines in which the components of rehabilitation were graded

\begin{tabular}{lcc}
\hline Component/outcome & $\begin{array}{c}\text { Chest 1997;112:1363-96 } \\
\text { (reference 10) }\end{array}$ & $\begin{array}{c}\text { Author's grading 2002 } \\
\text { (references 9,11,12) }\end{array}$ \\
\hline Lower extremity training & $\mathrm{A}$ & $\mathrm{A}$ \\
Upper extremity training & $\mathrm{B}$ & $\mathrm{B}$ \\
Ventilatory muscle training & $\mathrm{B}$ & $\mathrm{A}$ (against) \\
Psychosocial, behavioural and & $\mathrm{C}$ & $\mathrm{C}$ \\
$\quad$ educational components & & \\
Dyspnea & $\mathrm{A}$ & $\mathrm{A}$ \\
Quality of life & $\mathrm{B}$ & $\mathrm{A}$ \\
Health care utilization & $\mathrm{B}$ & $\mathrm{A}$ \\
Survival & $\mathrm{C}$ & $\mathrm{C}$
\end{tabular}

Note difference in the assessment of the importance of ventilatory muscle training and the benefits of rehabilitation on quality of life and health care utilization. Data taken from references 9,11,12

- These improvements have been associated with a reduction in health resource utilization.

- The benefits of rehabilitation diminish with time.

\section{IMPROVEMENTS IN HEALTH-RELATED QUALITY OF LIFE AND FUNCTIONAL EXERCISE CAPACITY}

Over the past 10 years, prospective, randomized, controlled trials employing valid reproducible and interpretable outcome measures have demonstrated the effectiveness of respiratory rehabilitation on exercise and health-related quality of life (Figure 5) (4-6). Rehabilitation programs are not sitespecific and can be delivered as inpatient (4), outpatient (6) or community-based programs (5). Meta-analyses of respiratory rehabilitation in $\operatorname{COPD}(7,8)$ have confirmed that most clinical trials of rehabilitation show small but consistent benefits that exceed the minimal clinically important differences, especially in the domains of dyspnea, fatigue and mastery (Table 1). 


\section{Change in CRDQ Compared with Baseline}

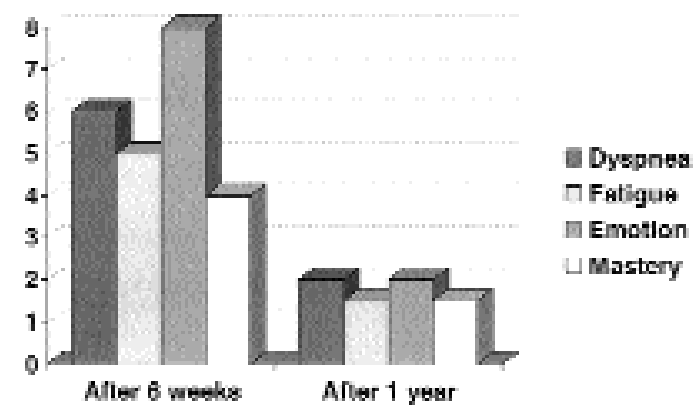

Figure 6) Results of outpatient rehabilitation showing that the improvements after six weeks have almost completely diminished by one year. CRDQ Chronic respiratory disease questionnaire. Data taken from reference 11

When the components of respiratory rehabilitation have been evaluated (Table 2) (9), reports have concluded that lower extremity training is essential (Grade 1A evidence) to achieve improvements in exercise tolerance and health-related quality of life. Although upper extremity training is also valuable, there are, as of yet, too few prospective, randomized, controlled trials of upper extremity training for a definitive assessment of evidence.

Although numerous trials of ventilatory muscle training (VMT) have been published, the evidence in support of its effectiveness, when VMT plus exercise training is compared with exercise training alone, is equivocal. The American College of Chest Physicians/American Association of Cardiovascular and Pulmonary Rehabilitation Guidelines rated this evidence as weakly favourable for VMT, but the Lacasse review was clear that the available trials demonstrated an absence of effect for VMT $(9,10)$. Unfortunately, there are too few studies to conclude that there is supporting evidence for psychosocial, behavioural or educational components of rehabilitation, although most rehabilitation programs include them. It appears that psychosocial support, in combination with exercise, reduces anxiety, promotes self-efficacy and improves exercise compliance.

\section{HEALTH RESOURCE UTILIZATION}

In a recent study, Griffiths et al (11) randomly assigned 200 patients with COPD to six weeks of outpatient rehabilitation versus a control group. After one year of follow-up, it was noted that although the total number of patients admitted to hospital with respiratory exacerbations did not differ between the study groups (41 patients - control group; 40 patients - rehabilitation group), those who completed rehabilitation spent fewer days in hospital (18.1 days - control group; 9.4 days - rehabilitation group) $(\mathrm{P}<0.05)$. Patients completing rehabilitation also required fewer primary care home visits $(2.8$ days - control group; 1.5 days - rehabilitation group) $(\mathrm{P}<0.05)$. A subsequent detailed economic analysis (12) established that the cost savings among the group that completed respiratory rehabilitation markedly exceeded the costs of the program itself.

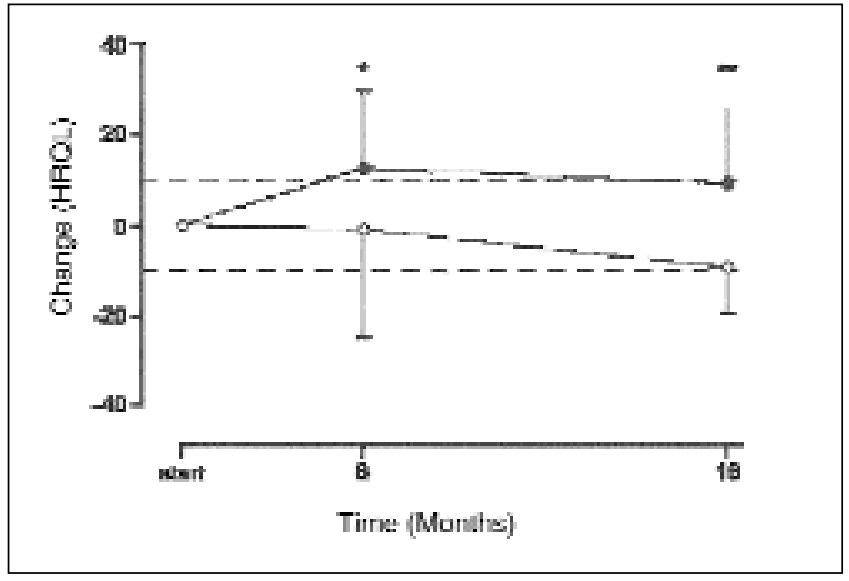

Figure 7) Changes in health-related quality of life (HRQL) with time following a six-month rehabilitation program. The improvements in quality of life are sustained at 18 months. Reprinted from reference 16, with permission from Excerpta Medica Inc

\section{The Long-Term effect of Pulmonary Rehabilitation on the 12 Minute Walk Distance Exercise maintenance vs. no malntenance}

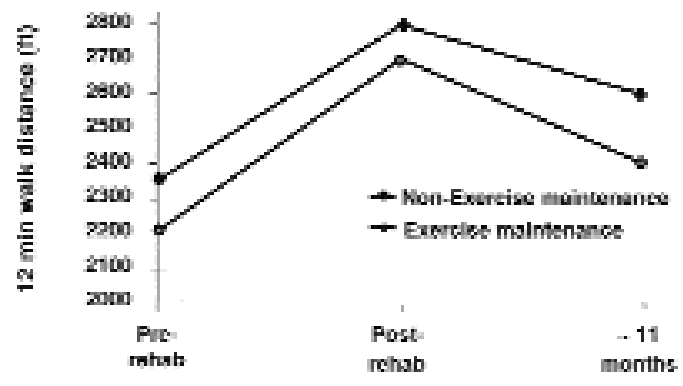

Figure 8) Data from a retrospective report on the effects of a maintenance program on exercise tolerance. Both subjects enrolled in the maintenance program and those who did not participate in maintenance deteriorated similarly over subsequent months. Reproduced from reference 17, with permission from Chest

\section{DIMINUTION OF BENEFITS WITH TIME}

Unfortunately, one year after outpatient rehabilitation, quality of life questionnaires often return to baseline values (Figure 6). This diminution of benefit has been reported in several programs (4-6,11). Longer programs may well extend the duration of improvement (13-15). Troosters et al (16) reported on 100 patients randomly assigned to a six-month program of rehabilitation. Differences in 6 min walk (52 m [95\% CI 15 to $89 \mathrm{~m}]$ ) and health-related quality of life (chronic respiratory questionnaire 14 points [95\% CI 6 to 21 points]) were both in excess of the minimal clinically important difference at 18 months (Figure 7).

\section{HOW BEST TO MAINTAIN IMPROVEMENTS FOLLOWING INTENSIVE REHABILITATION}

In a retrospective study, Vale et al (17) reviewed 51 patients 12 months after they had completed rehabilitation. Nineteen 
"Are you doing any regular excreises at home?"

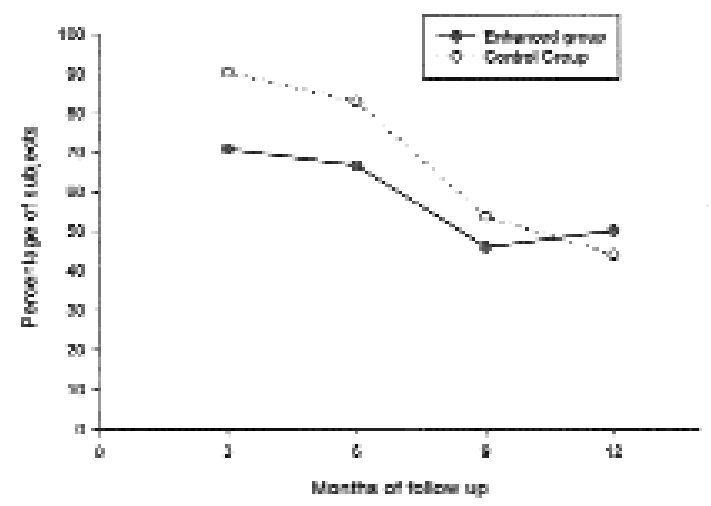

Figure 9) Self-reported compliance with rehabilitation in patients involved with an enhanced rehabilitation follow-up program, and control subjects showing a similar reductions in compliance with exercise over a one-year period. Reproduced from reference 18, with permission from European Respiratory Society Journals Ltd

\section{Compliance with Breathing Exercises}

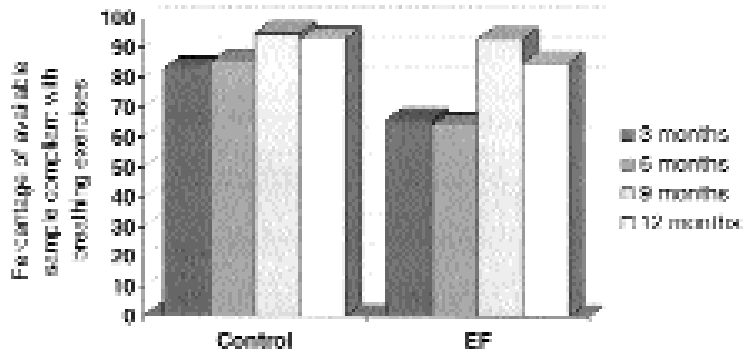

Figure 10) Influence of enhanced follow-up (EF) on compliance with breathing exercises, showing similarities between the two groups and an overall high level of compliance up to one year. Reproduced from reference 18, with permission from European Respiratory Society Journals Ltd

patients had participated in a weekly exercise maintenance program and 32 patients had not. Walking ability and quality of life were both reduced, with no between-group differences attributable to the maintenance program (Figure 8). In a recent prospective study, Brooks et al (18) reported the results of an enhanced post-rehabilitation follow-up program. Patients with severe, stable COPD (forced expiratory volume in $1 \mathrm{~s}$ less than $40 \%$, forced expiratory volume in $1 \mathrm{~s} /$ forced vital capacity less than 0.7 ) who completed rehabilitation were randomly assigned to receive enhanced follow-up or regular care. The enhanced follow-up group attended monthly supervised rehabilitation and were also called every four weeks (offset by two weeks from the group sessions). Control subjects received usual care. Both groups deteriorated with time (Figure 9). Although at six months the study group had better 6 min walk test results, by 12 months, there were no between-group differences in exercise capacity or quality

\section{Compliance with Interval Training}

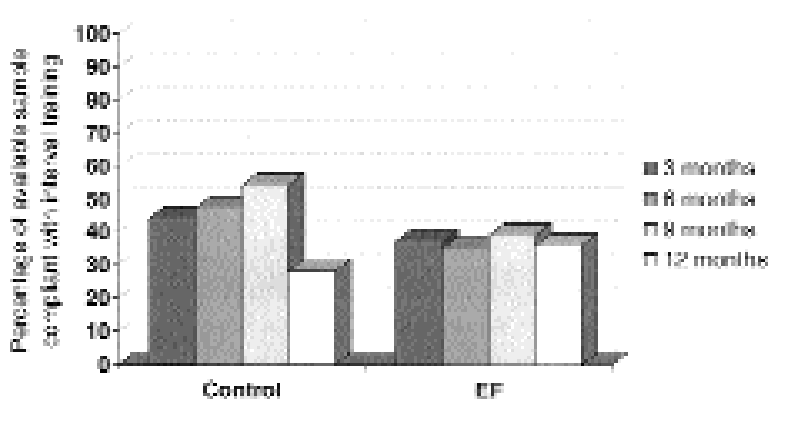

Figure 11) Influence of enhanced follow-up (EF) on compliance with interval training, showing similarities between the two groups. Both groups exhibit a low level of compliance, not influenced by the enhanced program over a 12-month period. Reproduced from reference 18 , with permission from European Respiratory Society Journals Ltd

of life. Adherence differed among exercises, and was greatest for breathing exercises and least for interval training (Figures 10 and 11). A high percentage of patients identified a respiratory exacerbation as the key contributor to noncompliance with rehabilitation $(60 \%$ and $43 \%$ at three months, and $78 \%$ and $80 \%$ at nine months for control and enhanced subjects, respectively).

\section{CONCLUSIONS}

Rehabilitation is beneficial for patients with chronic respiratory conditions. There is good evidence that it improves healthrelated quality of life and functional exercise capacity. Programs are not site-specific but can be administered in the community or at an institution. There is an important reduction in health resource utilization associated with outpatient rehabilitation. Benefits of rehabilitation diminish with time and are not influenced by regular maintenance visits to the rehabilitation centre. Compliance with rehabilitation depends on the type of exercise in question; it is higher for breathing exercises and lower for interval training. The current challenge is to identify approaches that will help to improve compliance and maintain the benefits of the acute rehabilitation program. It may well be that patients require the most attention immediately following an acute exacerbation.

\section{REFERENCES}

1. Murray CJ, Lopez AD. Alternative projections of mortality and disability by cause 1990-2020: Global Burden of Disease Study. Lancet 1997;349:1498-1504.

2. National Institute of Health - National Heart, Lung, and Blood Institute. Morbidity \& Mortality - 2002 Chartbook on Cardiovascular, Lung, and Blood diseases.

$<$ http://www.nhlbi.nih.gov/resources/docs/02_chtbk.pdf > (Version current at March 19, 2003)

3. Canadian Institute for Health Information, Canadian Lung Association, Health Canada and Statistics Canada. Respiratory Disease in Canada. Ottawa: Health Canada, 2001.

4. Goldstein RS, Gort EH, Stubbing D, Avendaño MA, Guyatt GH Randomised controlled trial of respiratory rehabilitation. Lancet 1994:344:1394-7. 
5. Wijkstra PJ, van der Mark TW, Kraan J, van Altena R, Koeter GH, Postma DS. Long-term effects of home rehabilitation on physical performance in chronic obstructive pulmonary disease. Am J Respir Crit Care Med 1996;153:1234-41.

6. Ries AL, Kaplan RM, Limberg TM, Prewitt LM. Effects of pulmonary rehabilitation on physiologic and psychosocial outcomes in patients with chronic obstructive pulmonary disease. Ann Intern Med 1995:122:823-32.

7. Lacasse Y, Wong E, Guyatt GH, King D, Cook DJ, Goldstein RS. Meta-analysis of respiratory rehabilitation in chronic obstructive pulmonary disease. Lancet 1996;348:1115-9.

8. Lacasse Y, Brosseau L, Milne S, et al. Respiratory rehabilitation in chronic obstructive pulmonary disease. In: The Cochrane Library, Issue 2. Oxford: Update Software, 2002.

9. Lacasse Y, Guyatt G, Goldstein RS. The components of a rehabilitation program: a systematic review. Chest 1997;111:1077-88.

10. Pulmonary rehabilitation: Joint ACCP/AACVPR evidence-based guidelines. ACCP/AACVPR Pulmonary Rehabilitation Guidelines Panel. American College of Chest Physicians. American Association of Cardiovascular and Pulmonary Rehabilitation. Chest 1997;112:1363-96.

11. Griffiths TL, Burr ML, Campbell IA, et al. Results at 1 year of outpatient multidisciplinary pulmonary rehabilitation: a randomised controlled trial. Lancet 2000;355:362-8.

12. Griffiths TL, Phillips CJ, Davies S, Burr ML, Campbell IA. Cost effectiveness of an outpatient multidisciplinary pulmonary rehabilitation programme. Thorax 2001;56:779-84.

13. Guell R, Casan P, Belda J, et al. Long-term effects of outpatient rehabilitation of COPD: A randomized trial. Chest 117:4:976-83.

14. Weiner P, Weiner M, Magadle R. Pulmonary rehabilitation in patients with chronic obstructive disease. Harefuah 1997;133:202-5.

15. Lake FR, Henderson K, Briffa T, Openshaw J, Musk AW. Upper-limb and lower-limb exercise training in patients with chronic airflow obstruction. Chest 1990;97:1077-82.

16. Troosters T, Gosselink R, Decramer M. Short- and long-term effects of outpatient rehabilitation in patients with chronic obstructive pulmonary disease: a randomized trial. Am J Med 2000:109:207-12

17. Vale F, Reardon JZ, ZuWallack RL. The long-term benefits of outpatient pulmonary rehabilitation on exercise endurance and quality of life. Chest 1993;103:42-5.

18. Brooks D, Krip B, Mangovski-Alzamora S, Goldstein RS. The effect of postrehabilitation programmes among individuals with chronic obstructive pulmonary disease. Eur Respir J 2002;20:20-9. 


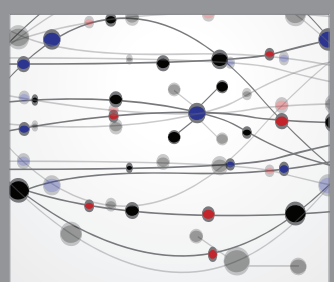

The Scientific World Journal
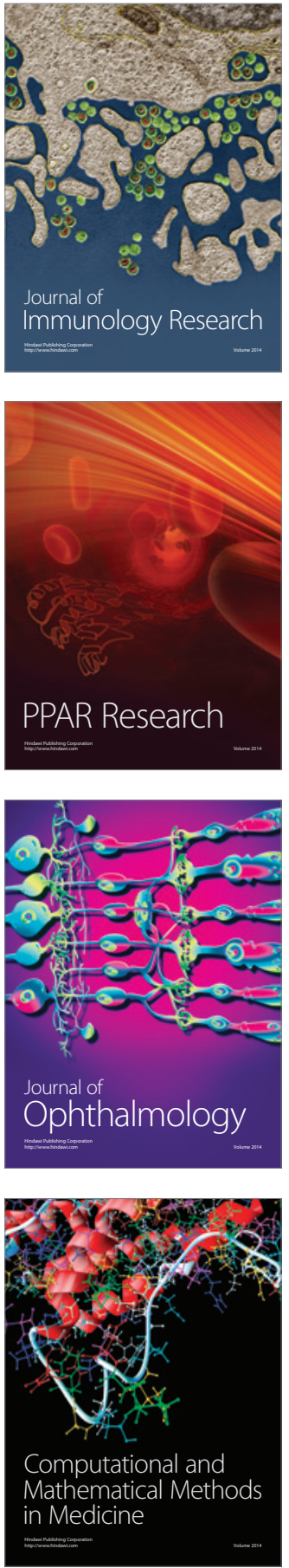

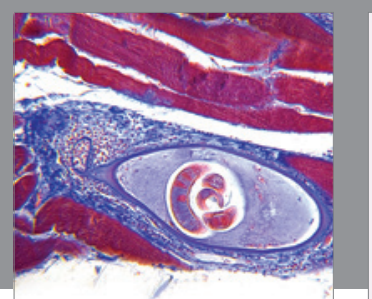

Gastroenterology Research and Practice

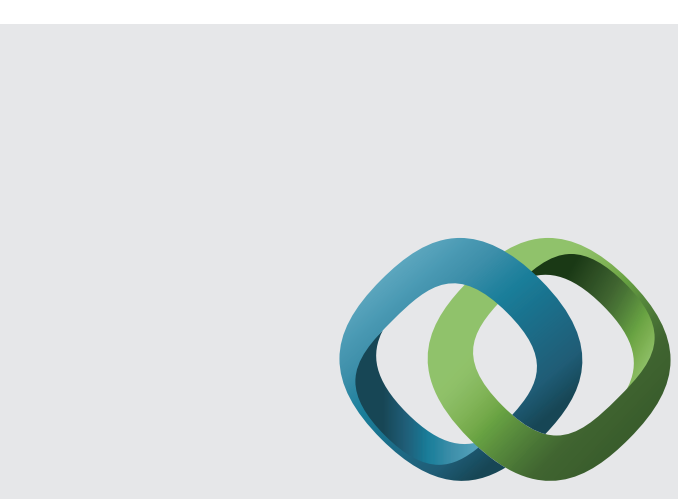

\section{Hindawi}

Submit your manuscripts at

http://www.hindawi.com
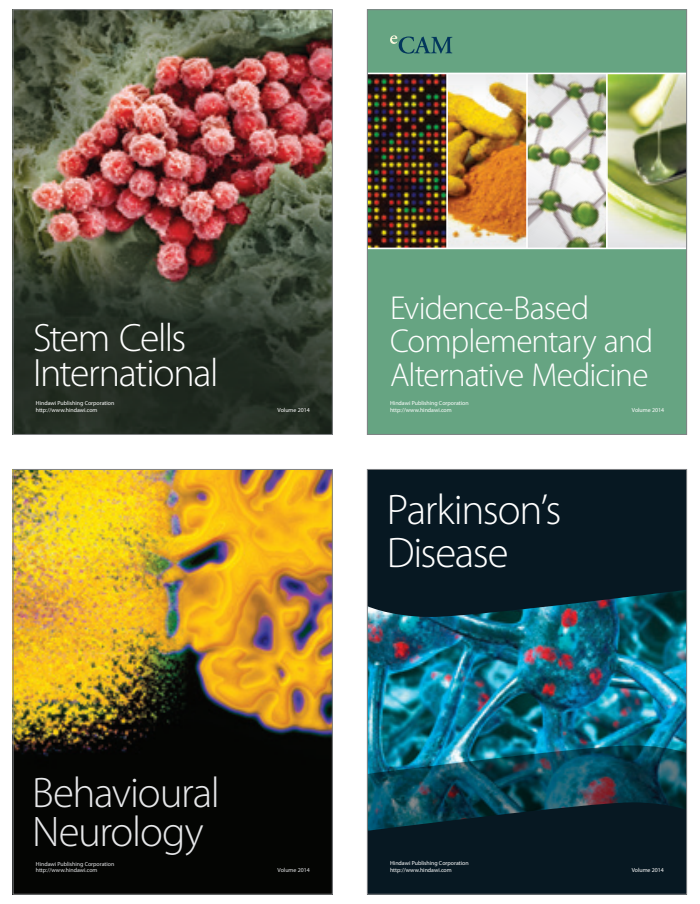
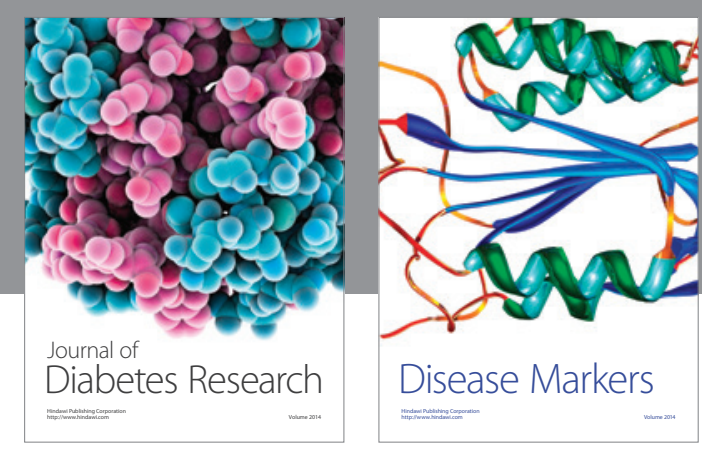

Disease Markers
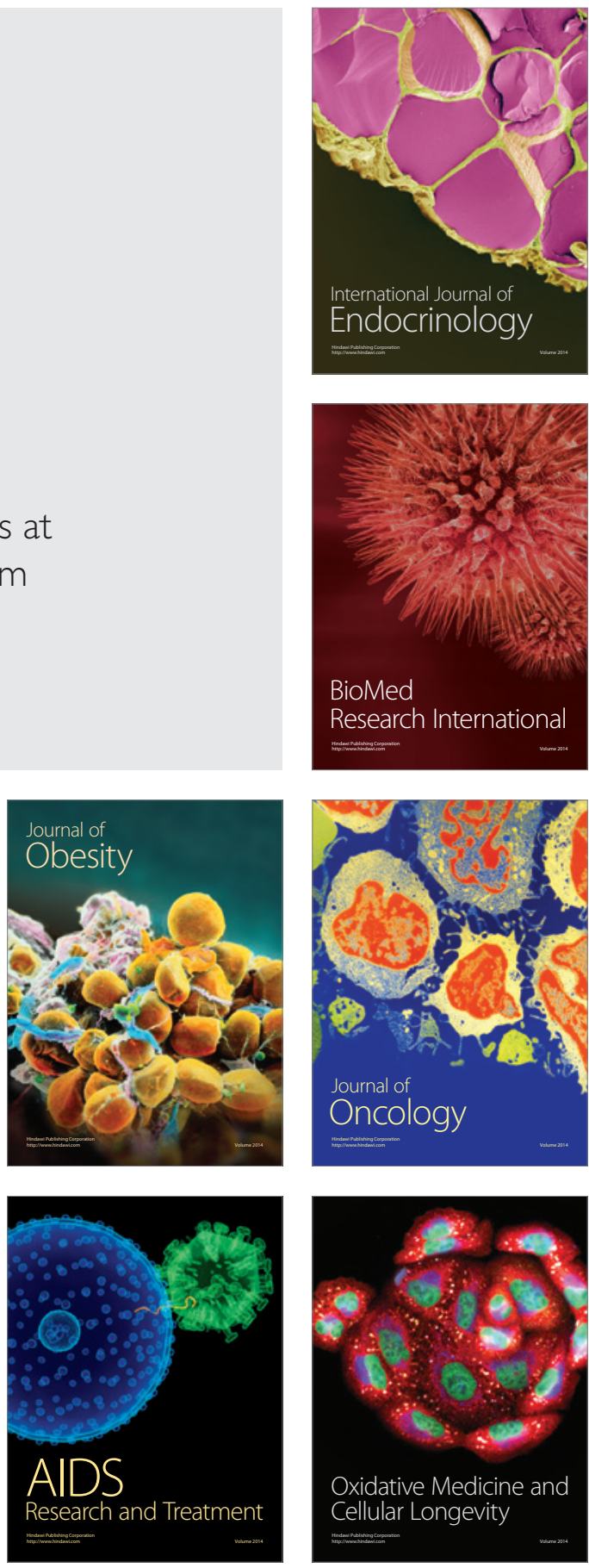